\title{
Galactic cosmic-ray effects on Fe and Ni isotopes in iron meteorites
}

\author{
D. L. COOK ${ }^{1,2 *}$, I. LEYA $^{3}$, AND M. SCHÖNBÄCHLER ${ }^{1}$
}

${ }^{1}$ Institute for Geochemistry and Petrology, ETH Zürich,

Clausiusstrasse 25, 8092 Zürich, Switzerland

${ }^{2}$ Earth Observatory of Singapore, 50 Nanyang Avenue,

Singapore 639798

( ${ }^{*}$ correspondence: david.cook@ntu.edu.sg)

${ }^{3}$ Space Science and Planetology, University of Bern,

Sidlerstrasse 5, 3012 Bern, Switzerland

Introduction: Galactic cosmic rays (GCRs) have the potential to induce changes in the original isotopic composition of iron meteorites [e.g., 1]. These changes may be mistaken for, or overprint, nucleosynthetic variations and/or affect isotopic chronometers [e.g., 2,3]. To explore potential GCR effects on $\mathrm{Fe}$ and $\mathrm{Ni}$ isotopes, we modelled GCR effects in iron meteoroids and compared the predictions to measurements of $\mathrm{Fe}$ and $\mathrm{Ni}$ isotopes in a suite of six IAB irons with a range of exposure histories as evidenced by their $\mathrm{W}$ and Pt isotopes [4].

Methods: Iron and $\mathrm{Ni}$ were separated via ion exchange chromatography and their isotopes were measured by MCICPMS at ETH Zürich [5]. The GCR production rates were calculated based on the model of [1] for meteoroids of various radii as a function of composition and depth below the surface for a cosmic ray exposure age of $1000 \mathrm{Ma}$.

Results and Discussion: Our GCR calculations show that neutron capture reactions dominate the effects on $\mathrm{Fe}$ and $\mathrm{Ni}$ isotopic ratios; spallation reactions are generally negligible. However, nearly all total GCR effects (neutron capture plus spallation) are smaller than the analytical uncertainty of the isotopic measurements for both $\mathrm{Fe}$ and $\mathrm{Ni}$. Measurements of $\mathrm{Fe}$ and $\mathrm{Ni}$ isotopes in the IAB irons are consistent with the GCR model predictions and are devoid of resolvable isotopic shifts relative to the terrestrial standards. Due to their relatively short exposure ages [6], GCR effects on $\mathrm{Fe}$ and $\mathrm{Ni}$ isotopes in chondrites are predicted to be even smaller than in iron meteorites. Thus, GCR effects on Fe and $\mathrm{Ni}$ isotopes in meteoritic samples are too small to mimic nucleosynthetic variations or to hamper the application of the ${ }^{60} \mathrm{Fe}-{ }^{60} \mathrm{Ni}$ chronometer.

References: [1] Leya \& Masarik (2013) MAPS 48, 665685. [2] Kruijer et al. (2013) EPSL 361, 162-172 [3] Cook et al. (2018) EPSL 503, 29-36. [4] Hunt et al. (2016) EPSL 482, 490-500. [5] Cook et al. (2020) MAPS in press. [6] Herzog G. H. \& Caffee M. W. (2014) Treatise on Geochemistry vol 1, 420-453. 